\title{
LA ACCIÓN EDUCADORA Y POLÍTICA DEL RITO, EN LA ANTIGUA CHINA
}

Mónica del Carmen Meza Mejía

\section{RESUMEN}

El sólido hilo que trenzaba -tejiendo- la antigua sociedad china, era el rito. La clase noble custodiaba los valores de la civilización y era el soberano el mediador entre el cielo (máxima deidad china) y el pueblo. Sólo los gobernantes eran hombres divinos: sólo ellos podían ser caballeros.

Contrario a la tradición, Confucio creía que cualquier hombre, si era íntegro, justo y bondadoso, llegaría a ser un caballero. En la ruta que conduce a la adquisición de la virtud y la sabiduría, el rito juega un papel fundamental.

El rito $-\boldsymbol{d}$ i es el principio que equilibra armónicamente al "hombre superior". El valor educativo del $\boldsymbol{l i}$ en la antigua China, radicaba en el hecho de que el rito manifiesta una representación cuya perfección formal, es reflejo de la unidad armónica entre el interior y el exterior de quien lo realiza. El $\boldsymbol{l i}$ es como la síntesis, pues, de todas las virtudes.

\section{INTRODUCCIÓN}

La antigua sociedad china poseía una intensa vida religiosa y de ceremonial, en la que participan todas las clases sociales. Los ritos festivos y celebraciones "eran vínculos que cruzaban la división de la sociedad ${ }^{1}$ y unían a todos los chinos en una gran civilización" ${ }^{2}$.

\footnotetext{
${ }^{1}$ La sociedad china se divide en la clase noble -duques (kung), príncipes (bou), marqueses (po), condes (tzu) y barones (na)-; los campesinos (nung); los comerciantes (shang); los artesanos (kung); y, apenas reconocidos como hombres verdaderos, se encuentran los esclavos que ni siquiera aparecen en la división tradicional de clases sociales establecida a finales de la antigüedad (Franke, H. y Trauzettel, R., El imperio chino., pp.32-34).

${ }^{2}$ Schafer, E., La China antigua., p. 42.
} 
La clase dirigente mantenía los valores fundamentales de tal civilización. Algunos de estos valores eran: el respeto, el amor filial, la realeza, la corrección en el cumplimiento ritual, entre otros. Quien mantenía bajo su cargo la máxima serie de funciones rituales era el soberano supremo - «wang - que, antes del siglo VI a.C., se creía recibía del cielo (principal deidad de los chinos) el mandato de gobernar en su nombre - «t'ien-ming,-.

De modo que los gobernantes en la cultura china, anterior a dicho siglo, "eran hombres, pero hombres divinos, servían de intermediarios entre su padre espiritual, el cielo, y el mundo de verdad, llamado "bajo el cielo"," ${ }^{3}$. El medio que comunicaba al soberano con sus divinidades y al gobernante con su pueblo, era el comportamiento ritual. Por eso, la corrección en el cumplimiento del rito reforzaba el ejercicio de la función pública y, en una primera instancia, otorgaba soberanía al gobernante.

Los antiguos chinos creían que si una nación era virtuosa, el cielo derramaría muchos dones sobre ella; contrario a esta situación, si la sociedad se alejaba de la virtud, pronto sufría calamidades (sequías, inundaciones, hambres, etcétera). En consecuencia, explica $\mathrm{Creel}^{4}$, quedaba establecido, teóricamente, el principio de que los gobernantes -Hijos del cielo: "Tien-tse" " existían para servir al pueblo, antes que a la inversa, y que retenían sus poderes sólo en depósito, como una especie de usufructo, susceptible de revocación si no hacían buen uso de ellos.

En la tradición china preconfuciana, se esperaba que todo gobernante fuera un "Hsïn-tzu" -literalmente "hijo de soberano" ${ }^{5}-$. El término, tiene un significado bastante similar al sentido originario de nuestro vocablo "caballero". Designa a un hombre de buena cuna, cuyos antepasados han pertenecido a un estrato social alto. De hecho, según las creencias de la

${ }^{3}$ Ibidem, p.79.

${ }^{4}$ Creel, H. G., El pensamiento chino desde Confucio hasta Mao tse-tung., p.30.

${ }^{5}$ Franke, H. y Trauzettel, R., op.cit., p. 42 . 
época, sólo quien poseyera origen semejante, podía convertirse en caballero, y ningún caballero podría degradarse de tal condición, por muy vil que fuese su comportamiento ${ }^{6}$.

Contrario a la tradición, Confucio (551-479 a.C.) consideraba que cualquier hombre llegaría a ser un caballero si era íntegro, justo y bondadoso. Con esta convicción, el sabio chino cambió la usanza de considerar al Hsün-tzu, sólo por su linaje. Afirmaba que para llegar a ser un Hsӥn-tzu, había que esforzarse, estudiar y formar el carácter. Estas dos últimas ideas las sintetizaba: "purificando virtud, investigando cosas" . Por tanto, a partir de entonces, cualquiera podía llegar a ser un caballero, si se hacía digno de ello.

En la etapa preconfuciana, la pauta tradicional para alcanzar el rango de caballero -tanto de los hijos de los reyes y aristócratas como de los hombres destinados a ser funcionarios menores en las cortes- se lograba, al parecer, mediante la enseñanza de técnicas que les permitieran desempeñar las funciones esperadas, según sus cargos. Confucio, en cambio, no se ocupó meramente de instruir y adiestrar a sus alumnos, sino de educarlos, en el sentido de "desarrollar y cultivar mental y moralmente, ampliar, fortalecer y disciplinar" ${ }^{8}$. Con ello, Confucio pretendió orientar a sus discípulos en la costumbre de la formación del caballero, pero también buscó educarlos para que supieran decidir bien a la hora de ejercer algún mandato que se les asignara.

Aunque los dos caminos tienen por objeto preparar al alumno para la vida pública, en el sistema tradicional se esperaba que el individuo fuera un simple instrumento de su soberano, poniendo en práctica lo que el príncipe deseaba que se hiciera y administrando el gobierno de la forma acostumbrada. Como contrapunto, en el sistema de Confucio, se esperaba que los alumnos desempeñaran el papel dinámico

\footnotetext{
${ }^{6}$ Creel, H.G., op.cit., p. 41.

7 Yáñez, M., Confucio., p.23.

${ }^{8}$ Creel, H. G., op.cit., p. 41.
} 
de perfeccionar cualquier gobierno en el que participaran y hacer que el ejercicio de éste sirviera a las necesidades del pueblo. "A este fin, era evidente que habían de prepararse para tan arduo cometido desarrollando al máximo su carácter, su inteligencia y su espíritu de iniciativa. No bastaría el mero adiestramiento en técnicas rutinarias" " . Como vemos, a partir de entonces el hombre llamado a gobernar, no designaba ya a una categoría social, sino a una cualidad moral -la del saber prudencial que, en el pensamiento de Confucio, se sustentaba como base de la sabiduría-. Un verdadero caballero es sabio, afirmaba él mismo, en la medida en la que "predica lo que practica" ${ }^{10}$.

La base de tal cualidad moral parte del conocimiento de uno mismo, de conocer la verdad de las cosas, de la rectitud de intención de hacer lo bueno y lo justo, y del esfuerzo para lograr la mejora individual-social. Para conseguirlo, aconseja el maestro chino, hay que aprenderlo desde el hogar en las relaciones filiales, como lo señala en las Analectas ${ }^{11}$ : «Un hombre que respeta a sus padres y a sus mayores difícilmente estará inclinado a desafiar a sus superiores. Un hombre que no esté inclinado a desafiar a sus superiores nunca fomentará una rebelión. Un caballero-sabio trabaja en lo esencial; una vez que

\footnotetext{
${ }^{9}$ Ibidem, p.42.

${ }^{10}$ Analectas., 2. 13.

${ }^{11}$ Las Analectas (recopilación) -también llamadas "Libro de los Coloquios" O “Lun-Yu» son una serie discontinua de afirmaciones breves, diálogos y anécdotas cortas. Es un texto recopilado por dos generaciones sucesivas de sus discípulos, a lo largo de unos 75 años tras la muerte de Confucio, lo cual significa que la recopilación probablemente se completa un poco antes, o alrededor, del año 400 a.C. "El texto es como un edredón multicolor hecho de piezas: son fragmentos que han sido cosidos juntos por diferentes manos, con una habilidad desigual, por lo que a veces existen algunas repeticiones, interpolaciones y contradicciones; hay algunos enigmas e innumerables grietas; pero en conjunto, se dan muy pocos anacronismos estilísticos: el lenguaje y la sintaxis de la mayoría de los fragmentos son coherentes y pertenecen al mismo período". Leys, S. Introducción en Analectas, pp.15-36. Para este trabajo, nos referimos al texto traducido por Alfonso Colodrón y editado por EDAF en 1998.
} 
lo esencial está asegurado, se desarrolla la Vía ${ }^{12}$. Respetar a los padres y a los mayores es la base esencial de la humanidad [ren], ${ }^{13}$.

La piedad filial - xiao"- "sirve de fundamento tanto al edificio moral, cuyo remate es la virtud de humanidad, como a las instituciones políticas" ${ }^{14} ; \boldsymbol{x i a o}$ es consecuencia de una simbiosis de Estado y familia en donde "el primero proporcionaba la base ideológica y los medios para hacerla penetrar en todas las capas de la sociedad, y la segunda, al aceptarlas, se constituía en el bastión que conservaba el orden para el estado" ${ }^{15}$.

En la familia tradicional china debemos buscar la raíz de la virtud pública, virtud que no se aprende por coerción sino por aceptación de sentimiento y obligaciones que tienen su origen en lazos de parentesco. "Así es como sentimientos que no son ajenos a otras culturas, tales como el amor y la gratitud hacia los padres, el respeto hacia ellos -que hace acatar su autoridad-, en China se vuelven algo más que sentimientos naturales universales" ${ }^{16}$. Por lo mismo, la piedad filial adquiere un lugar privilegiado entre todas las virtudes humanas, y es, según Confucio, lo que distingue al ser humano de las demás criaturas. Xiao es, en total, como señala María Ángeles Galino ${ }^{17}$, "la base de toda educación" y "tiene hondas raíces en el alma china”. Es el principio directivo para desarrollar el ijen", la práctica del bien ${ }^{18}$,

\footnotetext{
${ }^{12}$ La "Vía" es el "Tao" o camino al cielo al cual se llega siendo recto y virtuoso en la vida. Su meta es la felicidad en el sentido de alcanzar el Bien. Comprende cortesía y moralidad. Así también el Tao incluye, por un lado, el código ético del individuo, y, por el otro, las normas de gobierno que determinan la medida más plena posible de bienestar y autorrealización para cada ser humano (Creel, H.G., op.cit., p.47). Cabe señalar que este sentido del Tao es diferente al que da la escuela "taoísta", que lo consigue desde una actitud pasiva: "Haz sin hacer. Actúa sin acción...", Tao Te King, 63. Para este texto, nos remitimos a la versión e introducción de Ursula K. Le Guin.

${ }^{13}$ Analectas., 1. 2. Los corchetes son nuestros.

${ }^{14}$ Redondo, E., La educación en las antiguas culturas orientales., p.73.

${ }^{15}$ Botton Beja, F., Bajo un mismo techo. La familia tradicional en china y su crisis., pp.13-14.

${ }^{16}$ Ibidem, p.14.

${ }^{17}$ Galino, M.A., Historia de la educación., tomo 1., p.21.

${ }^{18} \mathrm{Fu}$, Pei-Jung., Human nature and human education. On human nature as tending toward goodness in classical confucianism., p.20. La traducción es propia.
} 
como un principio rector que busca la mejora en dos sentidos: el individual y el social, ya que para Confucio "el hombre moral no debe ser un número en la sociedad, sino un miembro colaborador de la misma" ${ }^{19}$.

El jen eleva al hombre a Hsün-tzu (caballero), al cultivarse a sí mismo y a Sben-je (sabio), al servir a otros. De donde, Hsïn-tzu -caballero- y Shen-je -sabio- son prototipos del hombre chino educado, que se ordena a la ley natural y que está perfectamente unido con el cielo ${ }^{20}$. "Cuando la naturaleza prevalece sobre la cultura, se tiene a un salvaje; cuando la cultura prevalece sobre la naturaleza, se tiene a un pedante. Cuando naturaleza y cultura están en equilibrio, se tiene a un caballero y a un sabio" ${ }^{21}$.

En la ruta que conduce a la adquisición de la virtud y la sabiduría, que dan forma al arquetipo del hombre educado, el rito juega un papel fundamental ${ }^{22}$. El rito $-\boldsymbol{k}$ - es el principio que lleva al equilibrio armónico de la fuerza reguladora y ejemplar que pertenece al caballero y al sabio, y juntos, al "hombre superior ${ }^{23}$. Para Confucio el cultivo intelectual es de escaso valor si no se acompaña del equilibrio emocional; es decir, de la educación de los sentimientos. El logro de tal equilibrio armónico depende de la educación en el $\boldsymbol{l} \boldsymbol{i}$. La formación del caballerosabio, señala Confucio, debe ser "disciplina" por medio de $\boldsymbol{l}$; Por el $\boldsymbol{l}$ el hombre se prepara para salir fortalecido al mundo; puede mantenerse fiel a sus principios en cualquier trance y delante de toda tentación ${ }^{24}$. "Estamos sin duda ante uno de los conceptos-clave de la concepción de la educación y de la forma de vida de la antigua China, y también ante un concepto central en la doctrina y forma de vida confucianas" ${ }^{25}$.

${ }^{19}$ Creel, H. G., op.cit., p. 45 .

${ }^{20} \mathrm{Kun}-\mathrm{Yu}$ WoO, P., The Metaphysical foundations of traditional chinese moral education., p.8. La traducción es propia.

${ }^{21}$ Analectas., 6. 18.

${ }^{22}$ Botton Beja, F., op.cit., p.17.

${ }^{23}$ Redondo, E., op.cit., p.74.

${ }^{24}$ Creel, H. G., op.cit., p. 46.

${ }^{25}$ Redondo, E., op.cit., p.76. 
La palabra " $\boldsymbol{i}$ " es polisémica y resulta difícil traducirla de forma literal en nuestro idioma. Es la correcta realización de las ceremonias, en tanto el conjunto de reglas de conducta adecuadas según las enseñanzas de los maestros y recogidas en el canon del Li-King o libro de los ritos ${ }^{26}$ y en los clásicos confucianos ${ }^{27}$. Es también lo que el Estado considera la guía para la conducta pública y para la misma ley ${ }^{28}$. El Li sigue de cerca las cinco relaciones básicas, fundamento de la sociedad china ${ }^{29}$ : amor entre padre e hijo; deber entre gobernante y súbdito; recato entre marido y mujer; respeto entre hermano mayor y hermano menor; confianza entre amigos.

Por consiguiente, $\boldsymbol{l}$ i equivale a "costumbre" y "ceremonia" o "etiqueta" ${ }^{30}$. En el primer sentido, el de "costumbre" se asemeja a "hábito", algo bueno que se repite muchas veces; en el segundo sentido "ceremonia" o "etiqueta", se asemeja a "cortesía", "urbanidad”. "Pero además el $\boldsymbol{l}$ incluye no sólo los ritos y costumbres, sino también su fundamento: la norma o disciplina moral individual y el ordenamiento político o estructura social en los que aquéllos se basan" ${ }^{31}$. A este fin combinadas, las normas de moralidad y de urbanidad o cortesía, se refuerzan entre sí.

De esta forma se continúan y complementan el ámbito privado de la familia y el ámbito público del Estado. Las normas de conducta que impone el $\boldsymbol{l}$ son aprendidas y practicadas

\footnotetext{
${ }^{26}$ El Li-King, desarrolla cada uno de los géneros de ceremonia (bodas, funerales, audiencias, peticiones de mano, fiestas populares, vestimenta, sacrificios, protocolo de los huéspedes, protocolo del ejército, etcétera), de modo que quien lo observe pueda aspirar a proceder en todo momento como es debido, esto es, de acuerdo con las costumbres autorizadas (Galino, M. A., op.cit., tomo 1, p.24).

${ }^{27}$ Los clásicos confucianos son obras atribuidas a Confucio y a sus discípulos: 1) El Lun-Yu, al que ya nos hemos referido en una cita previa. 2) El Ta-Shio o "Gran Estudio", también llamado Ta Hsueh (Gran Enseñanza). 3) El Tchunyung o "Libro del Justo Medio" o "Doctrina del Justo Medio". 4) El Meng-Tsé o "Libro de Mencio", principal discípulo de Confucio (Redondo, E., op.cit., p.80).

${ }^{28}$ Botton Beja, F., op.cit., p.14.

${ }^{29}$ Cfr. Ibidem, p.16.

${ }^{30}$ Redondo, E., op.cit., p.76.

${ }^{31}$ Idem.
} 
dentro de la familia, pero a la vez están registradas en los clásicos confucianos estudiados por todos los que aspiran a un puesto público, porque las mismas cualidades fundamentales que son necesarias para establecer la base moral de la autoridad en el gobierno, pueden encontrarse en las relaciones familiares. «El imperio tiene sus bases en el Estado, el Estado en la familia y la familia en el individuo" ${ }^{32}$, sanciona el pensamiento confuciano. De tal suerte, el $\boldsymbol{l}$ es un acto humano en donde concurren el intelecto, la voluntad y la corporeidad; es una actitud vital susceptible de enseñarse y aprenderse, y el modo como se logra su perfección, es mediante una práctica constante. Es, por ello asimismo, un acto educativo, además del de gobierno.

La educación supone unos modelos y se vale de unos recursos para reproducirlos. En el caso de la enseñanza y del aprendizaje del $\boldsymbol{l}$, podemos referirnos a dos ejemplos que nos explican la función del rito en la formación del caballerosabio: el primero, en la práctica del tiro al arco. El segundo, en el barrido con escoba.

En la antigua China, el tiro al arco se consideraba como el mejor medio para el dominio del rito. Las grandes pruebas de tiro al arco tenían como objetivo algo muy diferente a dar en el blanco; "atestiguan la mentalidad formal en estado puro" ${ }^{33}$; transforman el tiro al blanco en una disciplina interior, subordinado el éxito a la sincronización de los movimientos de cada participante en el conjunto de los gestos de los demás, a fin de contribuir a la armonía general. Ejecutado con música, podía considerarse como una verdadera coreografía. En el tiro al arco sólo ganaba el participante que pensaba menos en la victoria que en someterse a esa sintalidad en la que, ante todo, importaba seguir el ritmo, de manera que «un ejercicio

${ }^{32}$ Botton Beja, F., op.cit., p.16.

${ }^{33}$ Jean, L. P., Los funcionarios divinos: Política, despotismo y mística en la China antigua., p.137. 
que tenía por principio la mentalidad teleológica se sometía a la tiranía de la expresión formal " ${ }^{34}$. El propio proyecto de competición, nos refiere a la subordinación del espíritu a unos comportamientos que tienen como objetivo el respeto a la comunión formal del conjunto. Por razón de lo expuesto, percibimos que educar por medio del $\boldsymbol{l}$ "es crear unos comportamientos estereotipados que, debido a que están calcados de la armonía natural, jamás pueden enfrentarse» ${ }^{35}$.

Del mismo modo, el barrido formaba otro elemento indispensable, fundamental, de toda formación del niño chino para llegar a ser un hombre educado. El barrido con escoba era considerado un acto delicado y de una moral elevada. La actividad del barrido, describía cómo realizar a la perfección ese acto, al grado de convertirlo en ceremonia. Se examinaba minuciosamente cada gesto, se explicaba su razón de ser, la posición del cuerpo y la forma de proceder según el tamaño de las habitaciones. El barrido llevaba en sí mismo una lección, la mayor de las lecciones, más eficaz que cualquier clase expuesta con conceptos abstractos de moral. Expresaba, concretamente, una relación con el prójimo. Si los gestos se describían con lujo de detalles era porque transmitían un mensaje, cuyo sentido era bien intencionado. Esta tarea humilde no constituía, en modo alguno, un medio de rebajar el orgullo o de quebrantar las voluntades, como tampoco tenía por objeto manifestar una condición servil del discípulo para con su maestro. Permitía, en todo caso, delimitar los rangos y los deberes de cada uno y, por la minuciosidad de los gestos que requería, formaba una preparación a la actividad ceremonial. "No dan una lección de humildad, sino de urbanidad" ${ }^{36}$.

Por lo explicado, los movimientos rituales, se orientan en una doble dirección. Por un lado, el rito está dirigido a dar un

${ }^{34}$ Idem.

${ }_{35}$ Ibidem, p.138.

36 Ibidem, p. 152. 
orden interior, norma disciplinar de la vida privada y a regular el comportamiento externo, como norma de conducta y de urbanidad y de convivencia social. "En el primer sentido, el $\boldsymbol{l i}$ disciplina las pasiones, creando o restaurando el orden interior; en el segundo sentido, el $\boldsymbol{l}$ crea o restaura el orden exterior, el orden social" ${ }^{37}$.

El valor educativo del $\boldsymbol{l i}$ en la antigua cultura china, radicaba en el hecho de que el rito manifiesta una representación cuya perfección formal de quien lo realiza, es reflejo de la unidad armónica que hay entre su interior y lo exterior. No en balde, el gobernante tenía bajo su cargo las máximas funciones rituales en su reino; es decir, por medio de la corrección en los ritos, el gobernante creaba una red de correspondencia entre realidades de diferente orden: ordenaba la sociedad con la ley natural; esto atendiendo a la visión cósmica china, que integraba, por equilibrio armónico, universo, individuo, familia y pueblo; transmitía la tradición de generación en generación y creaba los vínculos que unían a todos los chinos, sin importar su condición social. También, como el $\boldsymbol{l i}$ es un conjunto de comportamientos rituales que se acatan por toda la sociedad, inferimos que cumple una función ejemplar paradigmática que se transmite en cascada. "Si el príncipe es personalmente correcto, regirá su Estado sin decretar leyes. Si es personalmente incorrecto, aunque promulgue leyes, éstas no serán observadas” ${ }^{38}$. Por el $\boldsymbol{l i}$, el gobernante mostraba a su pueblo que "sabía ser" lo que se esperaba de él y "sabía estar" a la altura del digno cargo que se le había encomendado porque, como reflejo de su virtud personal-social, dependía el futuro de su pueblo.

${ }^{37}$ Redondo, E., op.cit., p.76.

${ }^{38}$ Capitán Díaz, A., Historia del pensamiento pedagógico en Europa. Desde sus orígenes al precientifismo pedagógico de J. H. Herbart., p.10. 
De esta manera, el rito complementa y enriquece una competencia que apunta sólo a la mera tarea especializada: la humaniza con un fuerte contenido moral. Un «hombre superior", "amplía su conocimiento por medio de la literatura [por medio del estudio] y se refina con el ritual [con la norma moral]; por ello, no es probable que se equivoque» ${ }^{39}$. Es así que el gobernante de la antigua China, por medio del $\boldsymbol{l i}$, realizaba un doble acto: el de educación y el de gobierno ${ }^{40}$, ya que el $\boldsymbol{l}$ i es como la síntesis de todas las virtudes.

Comentamos por último, la gran similitud que encontramos en el pensamiento oriental y en el del ideal del humanismo occidental, que busca el bien personal aunado al bien de la comunidad a través de la práctica de la virtud, que se forma en torno a cuatro referentes universales: Unidad, Verdad, Bien y Belleza.

${ }^{39}$ Anacletas., 6. 27. Los corchetes son nuestros.

${ }^{40}$ Jean, L. P., op.cit., p.135. 
Analectas., versión y notas de Simon Leys., Madrid., EDAF., 1998. CAPITÁN DÍAZ, A., Historia del pensamiento pedagógico en Europa. Desde sus orígenes al precientifismo pedagógico de

J. H. Herbart., Madrid., Dykinson., 1984.

CREEL, H.G., El pensamiento chino desde Confucio hasta Mao Tse-tung., Madrid., Alianza., 1976.

FU, Pei-Jung., "Human nature and human education. On human nature as tending toward goodness in classical Confucianism", en Van Doan, T.; Shen, V. y McLean, G. F [eds.], Chinese foundations for moral education and character development., The Council for Research in Values and Philosophy., Washington.,1991., pp.19-28.

GALINO, M.A., Historia de la educación., Tomo 1., Edades Antigua y Media., Madrid., Gredos., 1960.

JEAN, L., Los funcionarios divinos: Política, despotismo y mística en la China antigua., Madrid., Alianza., 1991.

KUN-YU WOO, P., "The Metaphysical foundations of traditional chinese moral education", en Van Doan, T.; Shen, V. y McLean, G.F. [eds.], Chinese foundations for moral education and character development., The Council for Research in Values and Philosophy., Washington., 1991., pp.7-18.

Tao Te King, versión e introducción de Ursula K. Le Guin., Barcelona., Debate., 1999.

REDONDO, E., "La educación en las antiguas culturas orientales", en Redondo García, E. [dir.], Introducción a la Historia de la Educación., Barcelona., Ariel., 2001, pp.53-119.

SCHAFER, E. H., La China Antigua., Amsterdam., Proost and Brandt N. V., 1968.

YÁÑEZ SOlANA, M., Confucio., Madrid., Edimat., 2003. 